\title{
Erratum to: Animal cognition in a human-dominated world
}

\author{
Andrea S. Griffin ${ }^{1} \cdot$ Sabine Tebbich $^{2} \cdot$ Thomas Bugnyar $^{3}$
}

Published online: 16 January 2017

(c) Springer-Verlag Berlin Heidelberg 2017

\section{Erratum to: Anim Cogn \\ DOI 10.1007/s10071-016-1051-9}

In the original publication, the third author name was incorrectly published as Thomas Bugynar. The correct name should read as Thomas Bugnyar.

The original article has been updated.

The online version of the original article can be found under doi:10.1007/s10071-016-1051-9.

Andrea S. Griffin

andrea.griffin@newcastle.edu.au

1 School of Psychology, University of Newcastle, Callaghan, NSW 2308, Australia

2 Department of Behavioural Biology, University of Vienna, Althanstrasse 14, 1090 Vienna, Austria

3 Department of Cognitive Biology, Biologiezentrum, University of Vienna, Althanstrasse 14, 1090 Vienna, Austria 